\title{
EDITORIAL
}

\section{Clinicopathological Characteristics of Newly Diagnosed Colorectal Cancers in Community Gastroenterology Practice}

\author{
Chang Kyun Lee \\ Division of Gastroenterology, Department of Internal Medicine, Kyung Hee University School of Medicine, Seoul, Korea
}

\section{Article: Clinicopathological Characteristics of Colon Cancer Diagnosed at Primary Health Care Institutions (Intest Res 2014;12:131-138)}

Colorectal cancer (CRC) is a major health problem in most industrialized countries, with an annual incidence of 1 million cases, and an annual mortality of more than 550,000 cases. ${ }^{1}$ The incidence of CRC has been steadily increasing and, to date, the lifetime risk for CRC for an average-risk population is about $5 \%$ in industrialized countries. ${ }^{1}$ In Korea, recent nationwide cancer statistics data (the Korea National Incidence Database) show that the incidence of CRC steadily increased in both sexes from 1999 to 2010, and CRC was the third most commonly diagnosed cancer during $2010{ }^{2}$ Therefore, there is no doubt that CRC screening is an essential requirement for improvement of public health.

There are many screening tools for early detection of CRC, but cancer prevention is more likely to be achieved by procedures that are designed to both detect precancerous lesions and early cancer and to remove them concomitantly. To achieve this goal, there is no better option than colonoscopy. The National Polyp Study data clearly show that early detection and removal of adenomatous polyps through colonoscopy can reduce the incidence of CRC and prevent death from CRC. ${ }^{3,4}$ A recent trial involving 88,902 partici-

Received January 28, 2014. Revised February 3, 2014

Accepted February 3, 2014.

Correspondence to Chang Kyun Lee, Division of Gastroenterology,

Department of Internal Medicine, Kyung Hee University Hospital, Kyung

Hee University School of Medicine, 23 Kyungheedae-ro, Dongdaemun-gu,

Seoul 130-872, Korea. Tel: +82-2-958-8258, Fax: +82-2-968-1848, E-mail:

cklee92@paran.com

Financial support: None. Conflict of interest: None. pants followed over a period of 22 years reinforces the previous evidence. ${ }^{5}$ In this large prospective cohort study, lower endoscopy, including colonoscopy and sigmoidoscopy, was associated with reduced CRC incidence and mortality. ${ }^{5}$

In Korea, colonoscopy is extensively used at multiple levels of the health care system, from community gastroenterology practice to academic referral hospitals. Given the widespread and increasing use of colonoscopy as a screening examination for $\mathrm{CRC}$, it is important for clinicians to recognize the key clinical features of patients with newly diagnosed CRC and, more importantly, to recognize their endoscopic and pathologic characteristics of newly diagnosed CRC in community-level practice. This would enhance the strategy for care of patients with CRC and potentially improve the use of national colonoscopy resources.

In this issue of Intestinal Research, Park et al. report the clinicopathological characteristics of 579 newly diagnosed CRCs detected through elective colonoscopies performed by 60 community gastroenterologists at 19 primary health care institutions in Korea from January 2011 through December 2012. ${ }^{6}$ The main findings of their study follow. First, they reported the age-specific proportion of patients with newly diagnosed CRCs in community-level practice. Patients in their 50s were the largest group at $32.5 \%$, followed by those in their $60 \mathrm{~s}$ at $31.6 \%$ and those in their 70 s at $20.7 \%$. Patients older than age 50 accounted for $87.2 \%$ of all CRCs detected in this study, and the elderly (defined by the World Health Organization as $\geq 65$ years of age) accounted for $39.4 \%$ of all CRCs. Based on these results, the authors stated

๑ Copyright 2014. Korean Association for the Study of Intestinal Diseases. All rights reserved.

This is an Open Access article distributed under the terms of the Creative Commons Attribution Non-Commercial License (http://creativecommons.org/licenses/by-nc/3.0)

which permits unrestricted non-commercial use, distribution, and reproduction in any medium, provided the original work is properly cited. 
that "Our study indicates a novel trend of increase in occurrences of CRCs amongst younger demographics in recent years." I agree with the authors that the current results might partly reflect the identification of previously undetected disease with increased screening rates in the specific age group (50-59 years of age). Why is that? One of possible explanations is that the people 50-59 years of age are more likely to be economically active, so that they are more likely to have opportunistic screening by self-prompted request than older age groups.

The results by Park et al., however, do not indicate a true increase in the occurrence of CRCs in specific age groups, because this study is not a case-control or population-based study but a kind of case series. Much evidence indicates that the incidence of rate of CRC increases steadily with age. Surveillance, Epidemiology and End Results registry data indicate that CRC incidence was $74.5 / 100,000$ in persons 50-64 years of age, 186.0/100,000 in persons 65-74 years of age, and 290.1/100,000 in persons $\geq 75$ years of age. ${ }^{7}$ Another large prospective cohort study of average-risk patients (age 50 to 75$)$ undergoing colonoscopy also confirmed the trend of increasing incidence of advanced neoplasia including invasive cancer in elderly people: the prevalence of advanced neoplasia increased from $5.7 \%$ in persons $50-59$ years of age to $13 \%$ in persons $70-75$ years of age. ${ }^{8}$ According to recent nationwide cancer statistics data, the incidence of CRC also increased gradually with age in our country. ${ }^{2}$

Another major finding of the article by Park et al. is that one of three patients with CRC (28.2\%) had no symptoms related to CRC. Patients with right-sided colon cancer tended to have no or nonspecific symptom related to CRC, compared to patients with left-sided colon cancer who tended to have more specific symptoms related to CRC such as hematochezia $(P<0.001)$. Clinical symptoms related to CRC usually develop late in the course of the disease, which is why screening is so important. Undoubtedly, early detection and treatment are of more benefit than treatment at a later stage. The proportion of asymptomatic patients with CRC in the current study is much higher than those in several Korean studies, ranging from $2.1 \%$ to $10.6 \%$, but it is comparable to that of a study published in 2010 (in which $33.5 \%$ of patients were asymptomatic). ${ }^{6}$ Additionally, the CRCs in asymptomatic patients had some interesting features, such as "protruded" endoscopic appearance (58.3\%) and well-differentiated histology (57.1\%), as compared to CRCs detected in symptomatic patients $(P<0.05)$. The authors suggested that colonoscopy would provide a higher chance of endoscopic treatment and better prognosis in asymptomatic patients, as compared to symptomatic patients, who had more depressed lesions with undifferentiated histology. These data reinforce the current rationale of population-based CRC screening in average-risk asymptomatic persons. Moreover, these data provide important estimates that can be used in clinical practice with regard to the treatment strategy and prognosis of newly detected CRC.

However, several limitations of the study by Park et al. should be highlighted. The macroscopic classification of CRCs evaluated in their study was very arbitrary. Irrespective of the disease stage, the authors classified all eligible lesions with pathological diagnosis of adenocarcinoma into one of three macroscopic categories: "protruded", "flat" or "depressed", through their review of colonoscopic images. The endoscopic reviews in the current study were made by all participating gastroenterologists independently, not by central review. The authors arbitrarily incorporated two different macroscopic classifications that were developed for different stages of cancer (Kudo's classification for early CRC confined to the mucosal and submucosal layers, which includes type I [protruded], type II [flat], and type III [depressed], and Borrmann's classification, proposed in 1926 for "advanced" gastric tumors, which includes types 1 to 4 , for advanced or CRCs that invades through the proper muscle layer) into one new classification. Early CRC is, however, basically different from advanced CRC in terms of depth of invasion. A major reason why endoscopic classification for early gastrointestinal cancers exists separately is that only these lesions are the main targets for endoscopic treatment. A "protruded" early CRC is not the same as a "protruded" advanced CRC. Therefore, early CRC should be clearly distinguished from invasive CRC in a macroscopic classification, such as the "type 0 " lesion in the Japanese classification or the recent Paris classification. ${ }^{10}$

In summary, colonoscopy is the best, or at least, the preferred, method for screening for CRC. Although there has been widespread and increasing use of colonoscopy screening in community-level practice, little has been reported about community gastroenterologists' experience in Korea. With respect to this, the study by Park et al. in this issue of Intestinal Research is particularly interesting, in spite of several critical weaknesses, and I applaud their work in this field.

\section{REFERENCES}

1. Garborg K, Holme Ø, Loberg M, Kalager M, Adami HO, Bretthauer M. Current status of screening for colorectal cancer. Ann Oncol 2013;24:1963-1972. 
2. Jung KW, Won YJ, Kong HJ, Oh CM, Seo HG, Lee JS. Cancer statistics in Korea: incidence, mortality, survival and prevalence in 2010. Cancer Res Treat 2013;45:1-14.

3. Winawer SJ, Zauber AG, Ho MN, et al. Prevention of colorectal cancer by colonoscopic polypectomy. The National Polyp Study Workgroup. N Engl J Med 1993;329:1977-1981.

4. Zauber AG, Winawer SJ, O’Brien MJ, et al. Colonoscopic polypectomy and long-term prevention of colorectal-cancer deaths. N Engl J Med 2012;366:687-696.

5. Nishihara R, Wu K, Lochhead P, et al. Long-term colorectalcancer incidence and mortality after lower endoscopy. N Engl J Med 2013;369:1095-1105.

6. Park SH, Song CW, Kim YB, et al. Clinicopathological characteristics of colon cancer diagnosed at primary health care institutions. Intest Res 2014;12:131-138.
7. Day LW, Walter LC, Velayos F. Colorectal cancer screening and surveillance in the elderly patient. Am J Gastroenterol 2011;106:1197-1206

8. Lieberman DA, Weiss DG, Bond JH, Ahnen DJ, Garewal H, Chejfec G. Use of colonoscopy to screen asymptomatic adults for colorectal cancer. Veterans Affairs Cooperative Study Group 380. N Engl J Med 2000;343:162-168.

9. Yamano H, Kudo S, Tamegai Y, et al. Macroscopic classification of early colorectal carcinoma. Stomach and Intestine 2000;35:1485-1490.

10. Inoue H, Kashida H, Kudo S, et al. The Paris endoscopic classification of superficial neoplastic lesions: esophagus, stomach, and colon: November 30 to December 1, 2002. Gastrointest Endosc 2003;58(Suppl 6):S3-S43. 